\title{
Unsaturated seepage and stability of double-layer slope under rainfall infiltration
}

\author{
Yuan Zhang ${ }^{1}$, Haifeng $\mathrm{Lu}^{1 *}$ \\ ${ }^{1}$ School of Earth and Environment, Anhui University of Science \& Technology, Huainan, Anhui, 232001, China
}

\begin{abstract}
Taking a homogeneous double-layer soil slope as an example, the SEEP/W module and SLOPE/W module in the finite element analysis software GeoStudio were used in this paper. Then, the changes of pore water pressure and stability under different rainfall patterns and soil parameters were studied. Finally, the variation curves of pore water pressure and slope safety factor with rainfall time were obtained. The results show that: Soil parameters a and $\mathrm{m}$ are directly proportional to the slope safety factor, while $\mathrm{n}$ is inversely proportional to the slope safety factor. Under the condition of continuous rainfall, the decreasing rate of slope safety factor is directly proportional to the rainfall intensity.Under different rainfall patterns, the continuous rainfall in the advanced and normal rainfall patterns will cause the slope stability to decline and then gradually recover, while delayed and averaged rainfall patterns rainfall will cause the slope stability to decline continuously.In addition, there is a lag period in the change of slope safety factor, and the whole lag period lasts about 6 hours. During the lag period, the pore water pressure inside the soil began to decrease, while the slope safety factor continued to decrease. The safety factor starts to recover after the lag period ends.
\end{abstract}

\section{Introduction}

Slope instability is a common geological disaster in open pit mining. A large number of examples of slope instability indicate that rainfall is one of the main factors inducing landslides and debris flows ([1-2]). According to statistics, landslide accounts for $51 \%$ of geological disasters. Among them, the proportion of geological disasters caused by rainfall accounts for $90 \%$ of the total number of landslides([2-3]). The main reason of rainfall induced landslide is that the infiltration of rainwater causes the volumetric water content of soil to increase and the pore water pressure of soil to increase. The shear strength of the slope is reduced, causing the slope stability to decline.

At present, many researches have been carried out on the instability of soil slope induced by rainfall. These studies mainly focus on the influence of soil parameters, initial groundwater level, rainfall intensity and rainfall pattern, slope geometry and other factors ([1-6]). Tang Dong and others ([2])used unsaturated seepage analysis method to study the influence of early rainfall on the stability of different soil slopes. The influence of early rainfall on slope stability was preliminarily explored. The results show that the lower the permeability coefficient of slope soil, the greater the influence of early rainfall on slope stability and the longer the influence time. L. L. Zhang et al. ([7]) used the saturated-unsaturated seepage model of rainfall infiltration to study the effect of rainfall on the matrix suction inside the soil mass. Then the influence of matrix suction on slope stability was clarified. Yu Shuyang et al. ([8]) considered the seepage characteristics of shallow and deep sliding surfaces and the changes of slope stability under different rainfall types. The results show that different rainfall types affect the volumetric water content and pore pressure distribution of the soil, which leads to the change of slope stability.H. Rahardjo et al. ([6])discussed the influence of slope geometry, rainfall intensity and soil permeability on slope stability. They concluded that soil permeability and rainfall intensity are the main factors causing slope instability, while slope geometry only plays a minor role. The above research mainly focuses on the influence factors and change rules of single layer soil slope stability under the action of rainfall.

In view of the analysis of the stability of double-layer or multi-layer slope under the action of rainfall, the research focus of scholars at home and abroad is mainly to establish the infiltration model of rainfall and the influence of rainfall intensity and duration on the stability of slope. However, the study of soil parameters and rainfall types on slope stability is rare. On this basis, this paper taken a homogeneous double-layer soil slope as an example. Then the fluid-solid coupling model was used to analyze the influence of different soil parameters and rainfall types on slope stability changes. This provides a theoretical reference for the instability of double slope induced by rainfall.

\footnotetext{
* Corresponding author: luhaifeng7571@126.com
} 


\section{Stability analysis theory of soil slope under rainfall load}

\subsection{Calculation theory of unsaturated seepage}

According to the soil-water characteristic curve, Fredlund \& Xing model was proposed by Fredlund \& Xing ([9]) in 1994 to fit the soil-water characteristic curve. The specific expression is as follows:

$$
\theta_{\mathrm{w}}=C(\varphi) \frac{\theta_{s}}{\left(\ln \left(e+\left(\frac{\phi}{a}\right)^{n}\right)\right)^{m}}
$$

Where: $\theta_{\mathrm{w}}$ is the volumetric moisture content;

$\theta_{s}$ is the saturated volumetric moisture content; $e$ is the natural logarithm; $C(\varphi)$ is the correction factor; This article takes $C(\varphi)=1$;

According to the volumetric moisture content function of Fredlund \&Xing([9-10]), the permeability coefficient function can be estimated by knowing the saturated volumetric moisture content of soil. The specific results are as follows:

$$
k_{w}=k_{s} \frac{\sum_{i=j}^{N} \theta\left(e^{y}\right)-\theta(\varphi)}{\sum_{i=1}^{N} \frac{\theta\left(e^{y}\right)-\theta_{s}}{e_{i}^{y}} \theta_{0}\left(e_{i}^{y}\right)}
$$

Where: $k_{w}$ is the permeability coefficient corresponding to the negative pore water pressure; $k_{s}$ is saturated permeability coefficient; $y$ stands for dummy variable; $i$ is the numerical spacing between $j$ and $N ; j$ is the minimum negative pore water pressure; $N$ is the maximum negative pore water pressure; $\varphi$ corresponds to the negative pore water pressure in step $j ; \theta_{0}$ is the initial value of the equation.

\subsection{Calculation theory of slope stability}

For the stability analysis of unsaturated soil slope, the shear strength formula of unsaturated soil proposed by Fredlund et al. ([9])is adopted. As follows:

$$
\tau=c^{\prime}+\left(\sigma_{n}-u_{a}\right) \tan \varphi^{\prime}+\left(u_{a}-u_{w}\right) \tan \varphi^{b}
$$

Where: $\tau$ is the shear strength of unsaturated soil; $c^{\prime}$ is the effective cohesion of unsaturated soil; $\varphi^{\prime}$ is the effective internal friction angle of unsaturated soil; $\sigma_{n}-u_{a}$ is the static normal stress; $\sigma_{n}$ is the total normal stress; $u_{a}$ is pore gas pressure; $u_{a}-u_{w}$ is matrix suction; $u_{w}$ is pore water pressure; $\varphi^{b}$ is the friction angle corresponding to the contribution of matrix suction to shear strength. $\varphi^{b}$ usually decreases with the increase of matrix suction, which is assumed to be constant in this study.

\section{Calculation model and related parameters}

\subsection{Models and boundary conditions}

In this paper, the homogeneous slope model in reference 7 was modified as the slope model for this study([7]). Fig.1 shows the geometry and boundary conditions of the double-layer soil slope used in this study.

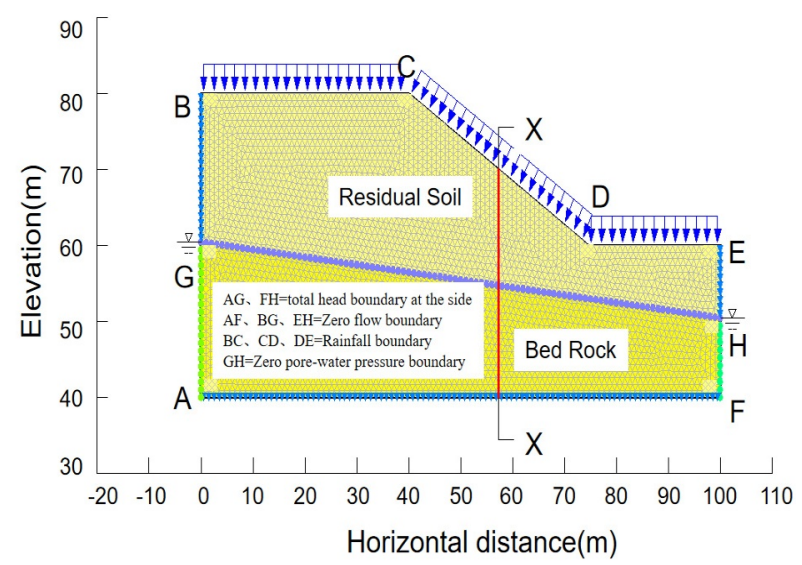

Fig. 1 Slope model and boundary conditions

The slope model has a slope height of $20 \mathrm{~m}$ and a slope angle of $30^{\circ}$. The slope is covered with residual soil and underlying bed rock. The specific boundary conditions of seepage flow are as follows: water head boundary is used on the left and right sides of bedrok, the total water head is $60.45 \mathrm{~m}$ and $50.45 \mathrm{~m}$, respectively. The top surface is zero pore pressure boundary, and the water head is equal to the elevation of the nodes on each surface. The boundary on both sides of the residual soil and the bottom of the slope are zero flow boundary.The top surface of the edge slope is the rainfall boundary, which is replaced by the flow boundary during simulation, and its specific value is equal to the rainfall intensity.A total of 29,175 grids and 14,854 nodes were divided into the model, as shown in Fig.1. The $\mathrm{x}-\mathrm{x}$ section was selected to monitor the pore water pressure, which was located at the connection between the middle of the slope and the bedrock surface.

Four rainfall patterns are used in this paper. They are advanced type, normal type, delayed type and averaged type respectively. Rain continued for 72 hours. The total rainfall of the four rainfall patterns is the same, and the relationship between rainfall intensity and total rainfall with time is shown in Fig. 2.

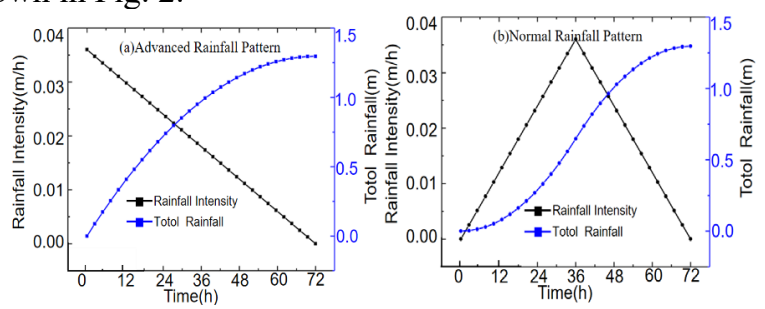

(a)Advanced Rainfall Pattern ;(b)Normal Rainfall Pattern; 

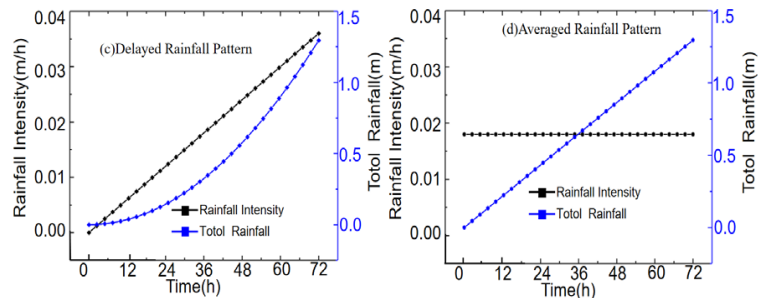

(c)Delayed Rainfall Pattern; (d)Averaged Rainfall Pattern

Fig. 2 Rainfall patterns

\subsection{Model parameter}

In the study of slope stability analysis under rainfall infiltration conditions, in addition to considering the influence of rainfall patterns, the influence of soil-water characteristic curves on slope stability was also considered. In reference 7 , the corresponding fitting parameters $\mathrm{a}, \mathrm{m}$ and $\mathrm{n}$ in the Fredlund-Xing model of soil water characteristic curve were selected as variables. Then the influence of soil-water characteristic curve shape on slope stability was studied. The physical and mechanical parameters of rock and soil are shown in Table 1. The soil-water characteristic curves corresponding to different $\mathrm{a}, \mathrm{m}$ and $\mathrm{n}$ are shown in Fig. 3 and Fig. 4.

Table 1 Parameters of slope model

\begin{tabular}{|c|c|c|c|c|c|c|}
\hline & $\begin{array}{c}\mathrm{K}_{\text {sat }} \\
(\mathrm{m} / \mathrm{s})\end{array}$ & $\theta_{\text {sat }}$ & $\begin{array}{c}\mathrm{c}^{\prime} \\
(\mathrm{KP} \\
\mathrm{a})\end{array}$ & $\begin{array}{c}\varphi^{\prime} \\
\left(^{\circ}\right)\end{array}$ & $\begin{array}{c}\varphi^{\mathrm{b}} \\
\left(^{\circ}\right)\end{array}$ & $\begin{array}{c}\gamma \\
(\mathrm{KN} / \\
\left.\mathrm{m}^{3}\right)\end{array}$ \\
\hline $\begin{array}{c}\text { Residual } \\
\text { Soil }\end{array}$ & $\begin{array}{c}1.0 \mathrm{e}- \\
5\end{array}$ & 0.4 & 10 & 26 & 26 & 18 \\
\hline $\begin{array}{c}\text { Bed } \\
\text { Rock }\end{array}$ & $\begin{array}{c}5.0 \mathrm{e}- \\
8\end{array}$ & 0.254 & 20 & 35 & 10 & 20 \\
\hline
\end{tabular}
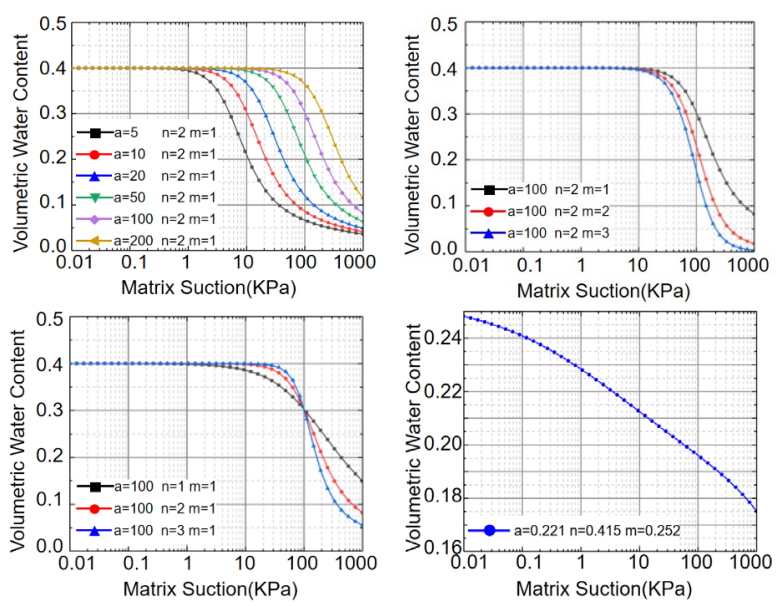

Fig. 3 Different parameters "a", "m”, "n”\&Bed Rock
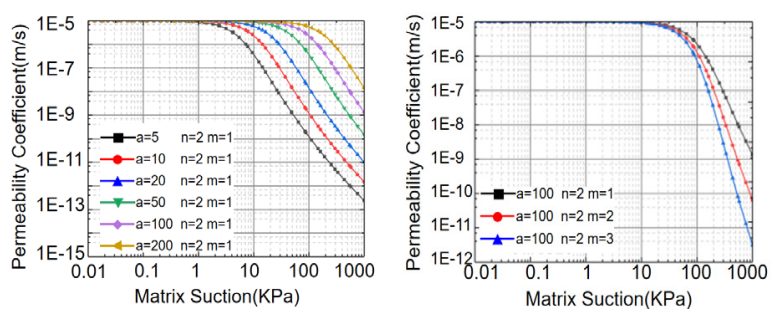

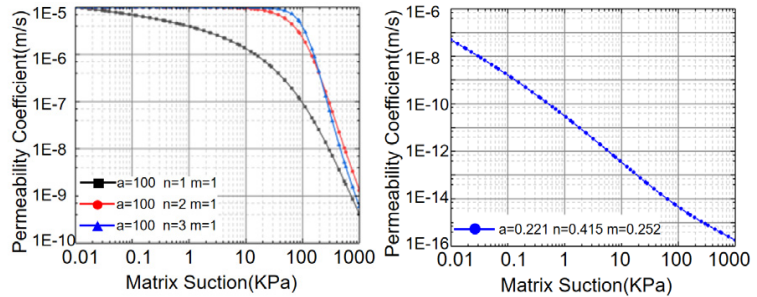

Fig. 4 Permeability coefficient of different parameters "a", "m", "n" \& Bed Rock

\section{Stability analysis of double-layer soil slope}

\subsection{Effect of parameter "a" in different rainfall patterns}

Fig. 5 is a graph showing the variation of safety factor with rainfall time under different rainfall patterns when $n=2, m=1$, and $\mathrm{a}$ is taken as 5,10,20, 50, 100 and 200 respectively. As can be seen from the figure, the larger a value is, the greater the safety factor of the double-layer soil slope is, and the more stable the slope is. Specifically, under the action of the same rainfall pattern, the slope safety factors of different a-value soils are affected differently by rainfall. The larger a-value is, the more obvious the slope safety factor is affected by rainfall. In combination with Fig. 3 and Fig. 4, it can be seen that the larger the soil property parameter a is, the larger the corresponding permeability coefficient and volumetric water content are.The faster the rainfall penetrates the soil, the faster the safety factor decreases, which is reflected in the slope of the curve of the safety factor over time.
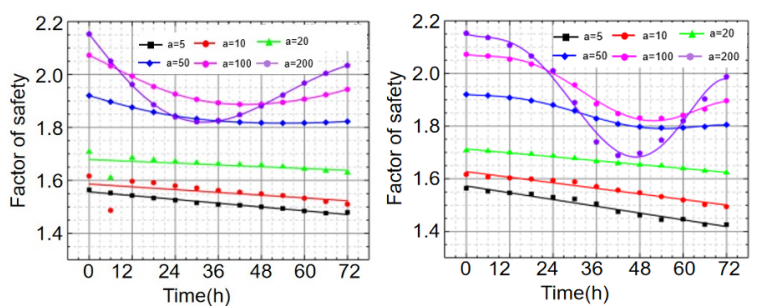

(a)Advanced Rainfall Pattern ;(b)Normal Rainfall Pattern;
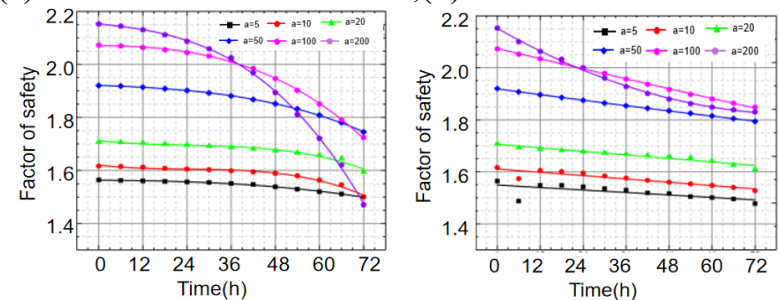

(c)Delayed Rainfall Pattern; (d)Averaged Rainfall Pattern

Fig. 5 Curves of safety factors- time for different a values

\subsection{Effect of parameter " $\mathrm{m}$ " in different rainfall patterns}

Fig. 6 is the variation curve of safety factor with rainfall time under different rainfall patterns when $a=100, n=2$, and $\mathrm{m}$ is 1,2 , and 3 respectively. $n$ general, the slope safety factors corresponding to different $m$ values change in the same trend under different rainfall patterns for the three soils. 
The slope safety factor and its change rate decrease with the increase of $m$ value.

When the rainfall patterns are advanced type and normal type, the slope safety factors-time curve is ' $\mathrm{V}$ ' type, similar to the soil parameter $a$. The difference is that for different $m$ values, when the slope safety factor falls to the lowest, the rainfall time experienced is similar. However, it can be seen from Fig.6 (a) and Fig.6 (b) that the smaller $m$ value is, the greater the range of variation of safety factors-time curve is. When the rainfall pattern is delayed type and averaged type, the slope safety factor decreases continuously.
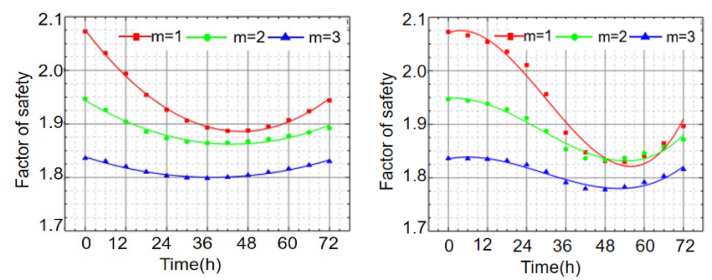

(a)Advanced Rainfall Pattern; (b)Normal Rainfall Pattern;
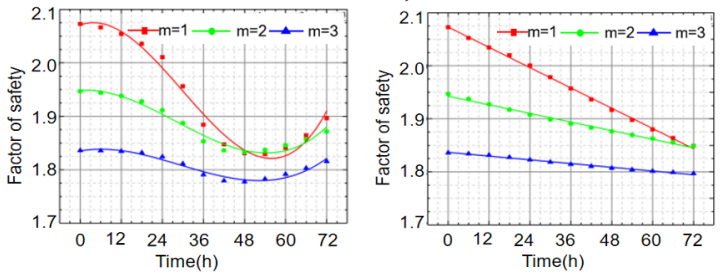

(c)Delayed Rainfall Pattern;(d)Averaged Rainfall Pattern

Fig. 6 Curves of safety factors-time for different $m$ values

\subsection{Effect of parameter " $n$ " in different rainfall patterns}

Fig.7 shows the curve of safety coefficient changing with rainfall time under different rainfall patterns when $\mathrm{a}=100, \mathrm{~m}=1$, and $\mathrm{n}$ is 1,2 , and 3 respectively. It can be seen from the figure that the initial safety factor of double-layer slope is basically the same under different $n$-value conditions. The variation trend of safety factor with rainfall time is the same. The smaller the value of $\mathrm{n}$ is, the lower the value of minimum safety factor is. In addition, the smaller the value of $n$, the greater the change of slope safety factor, the greater the range of change, and the greater the impact on the slope safety factor.
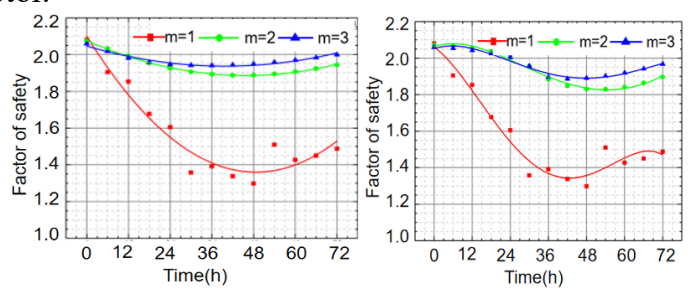

(a)Advanced Rainfall Pattern;(b)Normal Rainfall Pattern;
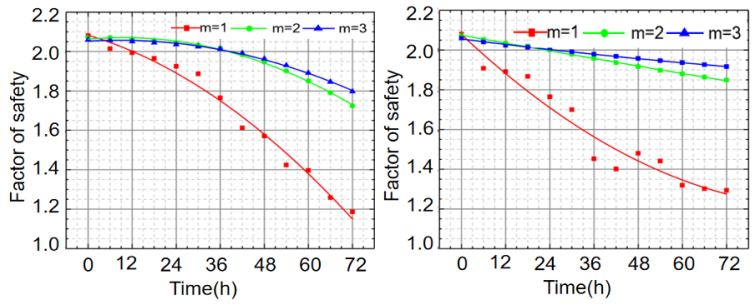

(c)Delayed Rainfall Pattern;(d)Averaged Rainfall Pattern

Fig. 7 Curves of safety factor-time for different $n$ values

\section{Discussion}

When the soil parameters $\mathrm{a}=100, \mathrm{~m}=1$ and $\mathrm{n}=2$, the relationship between the pore water pressure and the safety factor in the slope is analyzed under the four rainfall patterns.Fig. 8 shows Pore water pressure variation curve of slope section $\mathrm{X}-\mathrm{X}$ at different elevations.
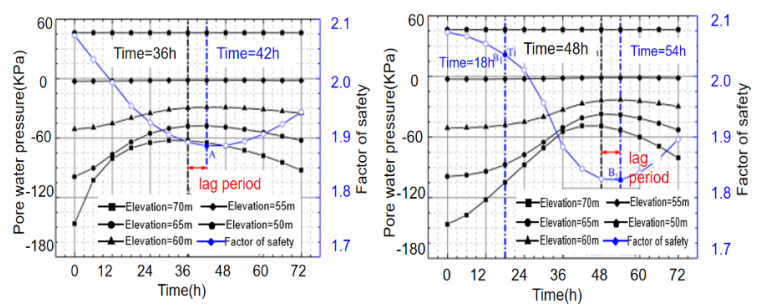

(a)Advanced Rainfall Pattern;(b)Normal Rainfall Pattern

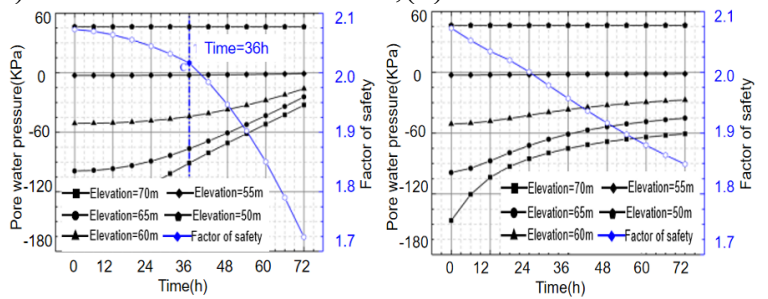

(c)Delayed Rainfall Pattern;(d)Averaged Rainfall Pattern

Fig. 8 Pore water pressure variation curve of slope section $\mathrm{X}-\mathrm{X}$ at different elevations

Fig. 8 shows the change curve of pore water pressure of sl ope section $\mathrm{x}-\mathrm{x}$ at different elevations under different rainfall patterns.It can be seen from Fig.9 that under the action of different rainfall patterns, the influence of rainfall infiltration on the pore water pressure in the shallow soil mass of the slope is greater than that in the deep. On the whole, the safety factor of the slope decreases with the increase of pore water pressure in the soil. However, there is a lag period in the change of slope safety factor, and the whole lag period lasts about 6 hours. In the lag period, the pore water pressure in the soil begins to decrease, while the safety factor of the slope continues to decrease. After the lag period, the safety factor begins to recover.

\section{Conclusions}

In this paper, double-layer soil slope is used as the calculation model to study the influence of different rainfall patterns and soil parameters on slope stability. The main conclusions are as follows:

(1) Different a values have different effects on slope stability. The larger the a value is, the better the slope 
stability is. When the value of a is small, rainfall mainly causes the change of pore water pressure in the surface soil of the slope, but has no effect on the pore water pressure in the deep soil of the slope. Therefore, the overall safety factor of the slope has little influence. When a value is large, the influence of rainfall on pore water pressure of slope soil extends to the deep part of soil, and has a great influence on safety factor of slope.

(2) Different values of $\mathrm{m}$ and $\mathrm{n}$ have different effects on slope stability. When the value of $\mathrm{m}$ is larger, the stability of the slope is worse, and the influence of rainfall on the safety factor of the slope is greater. Instead, when the value of $\mathrm{n}$ is larger, the stability of the slope is better, and the influence of rainfall on the safety factor of the slope is smaller.

(3) Different rainfall patterns have different effects on slope stability. When the values of $n$ and $m$ are the same and the value of a is small, the rainfall pattern has little influence on the slope stability. The safety factor of slope does not change much, and the minimum value appears at the time when rainfall stops in the early stage. When the value of a is larger, the change trend of slope stability is different under different rainfall patterns. The minimum safety factor of the slope and the time of occurrence are also different.

(4)There is a lag period in the change of slope safety factor, and the whole lag period lasts about 6 hours. During the lag period, the pore water pressure inside the soil began to decrease, while the slope safety factor continued to decrease. The safety factor starts to recover after the lag period ends.

\section{Acknowledgments}

This study was partially supported with the major projects of natural science research in Higher Education Institutions(KJ2019ZD11) and the research grants from the National Natural Science Foundation of China (41977253). The data used in this paper can be accessed by contacting the corresponding author directly.

\section{Reference:}

1. YAO Hailin, ZHENG Shaohe, LI Wenbin, et al. Parametric study on the effect of rain infiltration on stability of unsaturated expansive soil slope[J]. Chinese Journal of Rock Mechanics and Engineering, 2002,21(7): 1034-1039.

2. ZHOU Chuangbing, LI Dianqing. Advances in Rainfall-Induced Landslides Mechanism and Risk Mitigation[J]. Advances in Earth Science, 2009,24(5):477-487.

3. [3] SHI Zhenming, SHEN Danwei, PENG Ming, et al. Slope stability analysis by considering rainfall infiltration in multi-layered unsaturated soils[J]. Journal of Hydraulic Engineering, 2016,47(8):977-985.
4. [4]Rahimi A, Rahardjo H, Leong E C. Effect of hydraulic properties of soil on rainfall-induced slope failure[J].Engineering Geology,2010,114(3-4):135-143.

5. TANG Dong, QI Xiaohui, JIANG Shuihua, et al. Effect of different antecedent rainfalls and SWCCs on slope stability[J]. Chinese Journal of Geotechnical Engineering, 2015,37(s1):148-155.

6. Rahardjo H, Ong $\mathrm{T}$ H, Rezaur R B, et al. Factors Controlling Instability of Homogeneous Soil Slopes under Rainfall[J]. Journal of Geotechnical and Geoenvironmental Engineering, 2007, 133(12): 1532-1543.

7. Zhang L L, Fredlund D G, Zhang L M, et al.Numerical study of soil conditions under which matric suction can be maintained[J].Canadian Geotechnical Journal,2004, 41(4):569-582.

8. YU Shuyang, ZHANG Jixun, REN Xuhua, et al. Influence of Different Rainfall Patterns on Seepage and Stability of Shallow and Deep Landslides[J]. Water Resources and Power, 2018,36(3):123-127.

9. Fredlund D G, Xing A. Equations for the soil-water characteristic curve[J]. Canadian Geotechnical Journal, 1994, 31(4):521-532.

10. GEO-SLOPE International Ltd.Seepage Modeling with SEEP/W 2007[M]. Calgary, Alberta, Canada: Geo-Slope International Ltd.,2010.

11. Fredlund D G, Morgenstern N R, Widger R A. The shear strength of unsaturated soils[J]. Canadian Geotechnical Journal, 1978, 15(3):313-321. 